\title{
Use of Protein-Protein Interaction Network for Biomarker Identification in Oocyte Maturation
}

\section{Golzar Farhadi, Jamal Fayazi, Hedayat Allah Roshanfekr, Mahmoud Nazari, and Ellham Behdani}

Department of Animal Science, Faculty of Animal and Food Science, Agriculture Sciences and Natural Resources University of Khuzestan, Mollasani, Ahvaz, Iran

\section{Abstract}

Background: Oocyte maturation begins at the embryonic stage and continues throughout life. The effect of Follicle- Stimulating hormone (FSH) on gene of genes was

Corresponding Author:

Jamal Fayazi;

email: j_fayazi@ramin.ac.ir

j_fayazi@yahoo.com

Cell: +989166124162

Fax: +986136522425

Postal Code: 6341773637

Production and Hosting by

Knowledge E

(a) Golzar Farhadi et al. This article is distributed under the terms of the Creative

Commons Attribution License,

which permits unrestricted use and redistribution provided that the original author and source are credited.

Editor-in-Chief: Dr. Alireza Rafiei evaluated using GEO access codes for the data set GSE38345. Materials and Methods: The microarray data containing the gene expression information from cow oocytes show that their maturation is influenced by FSH. Data analysis was performed using GEO2R. After identifying the genes and examining the different genes expressed, two gene groups with increased and decreased expression were identified. The interaction of each of the gene groups was examined using the STRING database, based on the co-expression information. The meaningful sub networks were explored using the Clusterone software. Gene ontology was performed using the comparative GO database. The miRNA-mRNA interaction network was also studied based on the miRWalk database. Finally, meaningful networks and subnets obtained by the Cytoscape software, were designed. Results: Comparison of oocyte gene expression data between the pre-maturation and post- maturation stages after treatment with FSH revealed 5958 genes with increased expression and 4275 genes with decreased expression. Examination of the protein interaction network among the set of increased and decreased expression genes based on string information revealed 262 genes with increased expression and 147 genes with decreased expression (high confidence (0.7) data). RPS3, NUSAP1, TBL3, and ATP5H showed increased expression and were effective in the positive regulation of rRNA processing, cell division, mitochondrial ATP synthesis coupled proton, and in oxidative phosphorylation and progesteronemediated functions. WDR46 and MRPL22 showed decreased expression, which were important in the regulation of SRP-dependent co-translational proteins targeting the membrane, RNA secondary structure, unwinding, and functional pathways of ribosomal and RNA polymerase. The most important miRNA genes in the protein network of increased and decreased gene expression were bta-miR-10b-5p and miR-29b-2-5p. Conclusion: Examination of the genes expressed in the oocyte maturation pathway revealed nuclear, mitochondrial, and miRNA genes. Increasing and decreasing gene expression helps maintain equilibrium, which can be a biological marker.

Keywords: Oocyte maturation, Microarray data, expressed genes, FSH hormone

\section{G OPEN ACCESS}




\section{Introduction}

Recent procedural developments have helped in improving or inhibiting reproductive processes. Progress in reproductive efficiency can have a significant impact on the yield of livestock production. With the development of productive traits such as growth rate and milk production, the physiological and metabolic pressures on livestock have increased. Therefore, maintaining high reproductive performance in the future will be more difficult and development of effective methods for reproductive processes is necessary. Further issues in the field have been identified with the advent of technologies which generate a large amount of data for researchers. The most important of these technologies is microarray technology and RNA-seq in particular, which have led to another phase of systemic method development for complex organisms such as mammals [1]. In the past decade, microarray has been considered as a high-performance method for the analysis of gene expression, in order to study genomic data for a wide range of genes.lt is a low-cost, effective, and sufficient technology and can be used to simultaneously analyze expression of thousands of genes in the shortest possible time, and has generated a large amount of gene expression data in recent years [2]. Gene networks help to evaluate the most important genes in a physiological process and the graph theory is used to produce and reproduce biological networks. In biological networks, genes, proteins, or any other molecule that plays a role in the cell can be considered as a node and the relationship between different nodes is considered as an edge. Information about the relationship between genes and proteins can be stored in various databases based on the type of network [3]. In order to explore these communications, various algorithms have been developed [4]. In a study on the gene expression network to understand the molecular mechanisms of coronary artery disease (CAD) by Liu et al, the most important module related to cardiomyopathy pathways was identified. In addition, 30 high expression genes were described and two genes G6PD and S100A7 were identified as key molecules in this disease [5]. In another study by Uddin et al, the decline in normal brain function including learning disabilities, was observed in some persons. This study was aimed at understanding the molecular mechanisms in age-related learning disabilities (ASLI). In this study, we used a mathematical model used in the Gene Correlation Network Analysis Weighted Gene (IWGCNA) for the creation and comparison of genetic network models, in young and adult rat brain. The main goal of the identification of new ASLI genes and their networks was based on the co-expression of the genes. This analysis identified a set of network modules in young persons, each of them consisting of diverse and distinct genes with 
different biological applications. In this study, a single module was identified which included related genes in learning paths. Network analysis of this model of learning and memory in healthy and unhealthy mice allowed us to identify a collection of important genes in ASLI. The known function of these genes shows that they play a key role in important pathways, including the activity of kinase and phosphatase, the function of ion channels and the preservation of neural integration in memory formation [6]. Medina et al examined the co-expression network of Type 1 diabetes (T1D). T1D is a complex disease triggered by the autoimmune degeneration of insulin-producing pancreatic beta cells, which leads to the inability of the body to yield insulin. By analyzing a network based on interactions between specific genes or proteins involved in diabetes, Novel Coexpression gene network modules associated with T1D were elucidated, which in turn provide the basis for identifying potential pathways and biomarker genes that may be involved in the development of T1D [7]. In the present study, we used gene expression data to study the effect of follicle stimulating hormone $(\mathrm{FSH})$ on the expression pattern of the most important genes in oocyte development. The gene network was used for this purpose. In addition, the most important biological pathways were investigated in order to understand the mechanisms of the effect of this hormone on oocyte maturation.

\section{Materials and Methods}

\subsection{Data implementation}

In this study, GEO access codes for the data set GSE38345 from the NCBI database (https://www.ncbi.nlm.nih) were used to investigate the effect of the FSH hormone on the expression of genes. These data contain gene expression information from in vitro studies on the influence of the FSH hormone on cow oocytes, using microarray technique [8].

\subsection{Data analysis and identification of differently expressed genes}

The quality of the implemented data was evaluated and the data was normalized if necessary. Data for gene expression was analyzed and compared for two cases using the GEO2R software link, one before maturation (20 hours after oocyte treatment with FSH in laboratory conditions) and another after maturation ( 96 hours after oocyte treatment with FSH in laboratory conditions). 


\subsection{Gene networks and gene ontology}

After identification of the genes and examination of the different genes expressed, two gene groups were created, one for the genes with increased expression and another for decreased expression. The interaction of each of the gene groups was examined using the STRING database (https://string-db.org/), based on the Co-expression information. The STRING database is a global database for reviewing and analyzing these interactions. Graphical representation of the generalized protein interaction network provides a better understanding of functional interactions and facilitate basic analysis of biological processes [9]. In addition to direct binding, protein-protein interactions can also proceed indirectly through sharing of a substrate in a metabolic pathway, modulation of proteins, or participation in formation of large protein complexes. In fact, these functional interactions between proteins can often be derived from linkages between the genes that encode them. Genes should be maintained together and modulated, so that coded proteins can interact at a particular time and place in the cell. Meaningful sub networks were found by using Cluster one (v1.0) software, which is a method for detecting potentially overlapping protein complexes from protein-protein interaction data [10].

Network imaging and meaningful sub network analysis was performed punctuations (v3.6.0) software. The network analysis was used to identify new biomarkers from the collected data. The Network Analyzer plugin in the Cytoscape software was used for this purpose, which computes and displays a comprehensive set of topological parameters including the number of nodes, edges and connected components, density, radius, diameter, concentration, heterogeneity and clustering coefficient, characteristic path length and the distributions of node degrees, average clustering coefficients, and the shortest path length [11].

Gene ontology (GO) analysis was performed using the comparative $\mathrm{GO}$ database (www.comparativego.com). This database relies on the GO to classify the new functions of genes and proteins, and define punctuations molecular function, biological and cellular processes of genes and proteins. Comparing the distribution of genes and proteins from different samples can improve the understanding of biological pathways, and can also help discover genes associated with specific functions for example for therapeutic purposes. The program can also be expanded to integrate gene expression levels with the GO approach, leading to a more precise selection of important genes from different biological sources [12]. 


\section{4. miRNA-mRNA networks}

The interaction of miRNAs and mRNAs was carried out based on the miRWalk database (http://zmf.umm.uni-heidelberg.de/apps/zmf/mirwalk/) using predicted and published microRNAs, and was visualized by the Cytoscape software. The miRNAs which decreased or increased gene expression was studied by the miRWalk database. Also, the association of miRNAs that increased expression was studied with the genes that decreased expression. The miRWalk database offers latest information on gene miRNA interactions. A structured and intuitive interface lets users to efficiently capture data, make statistical analyses, visualize and download gene-miRNA networks. This integrative approach allows users to easily identify important miRNA targets to well recognize the roles of multiple miRNAs and optimize their gene targets [13]

\section{Results}

\subsection{Comparison between oocyte gene expression data in the pre- maturation and post- maturation stages}

Comparison between oocyte gene expression data in the pre-maturation and post- maturation stages after treatment with $\mathrm{FSH}$, showed that 5958 genes were expressed significantly higher in the post-maturation stage than in the pre- maturation stage and 4275 genes showed decreased expression. Protein interactions were determined in the genes with increased and decreased expression. 262 genes among the genes with increased expression and 147 genes among the genes with decreased expression were co-expressed based on information from the STRING database (high confidence (0.7) data).

\subsection{Protein-protein interaction (PPI) network analysis of up-regulated genes}

The oocyte development process by FSH has been shown in Figure 1. The number of genes involved in oocyte maturation based on the Gene Interaction Network were divided into the meaningful sub networks using Clusterone. Figure 2 shows a general overview of the two sub networks and Table 1 shows the genetic listing of the four sub networks. The Clusterone software shows the interaction of the proteins associated with the genes with increased expression and identified four significant sub networks. The 
number of nodes in the subnetworks $1,2,3$, and 4 in the expression genes $40,25,16$, 11 and the number of edges (1403) were determined.

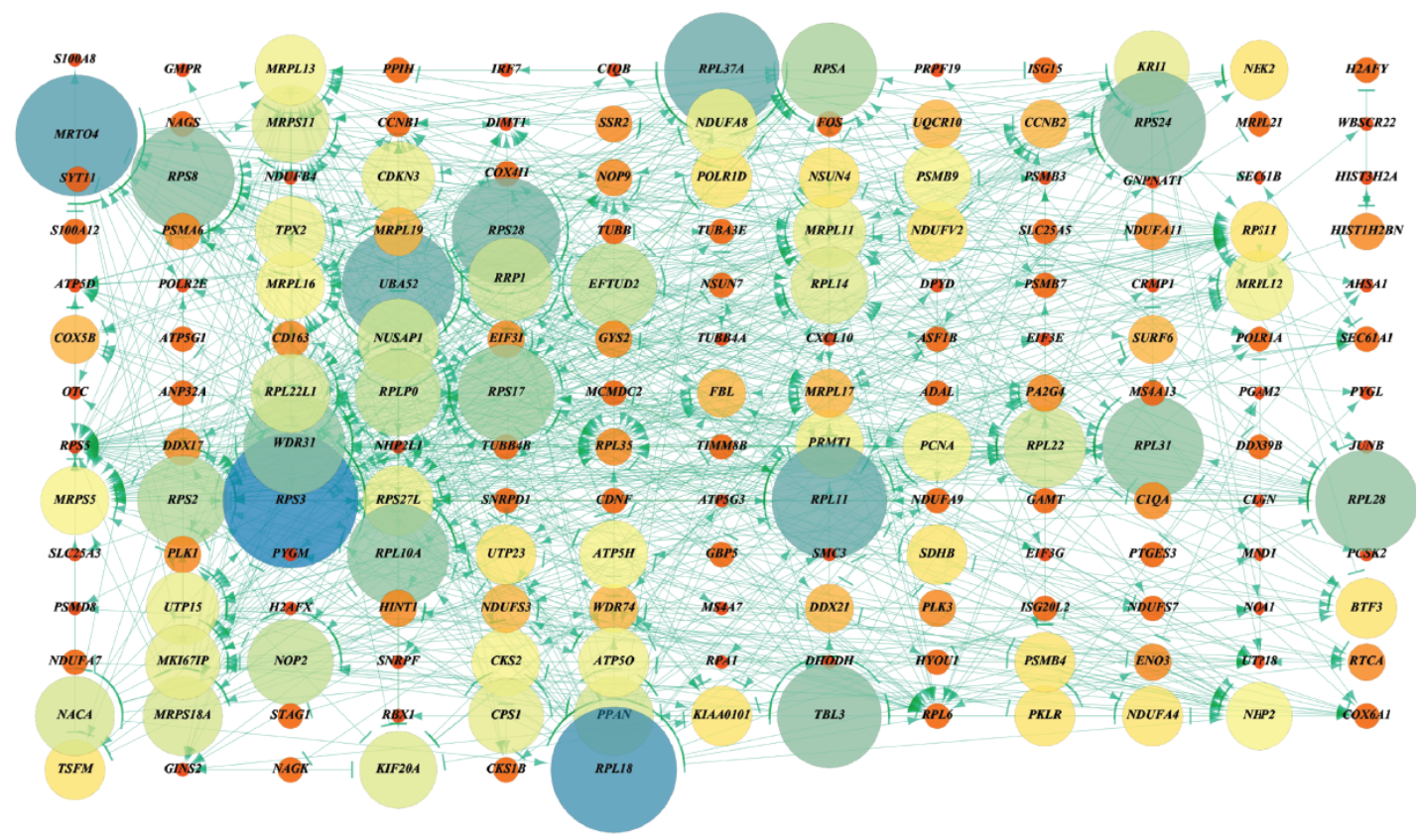

Figure 1: PPI network of up-regulated genes. The general set of genes with increased expression have been shown in the oocyte maturation process.

TABLE 1: The genetic information of subnetworks of up and down-regulated genes.

\begin{tabular}{|l|c|}
\hline & Cluster \\
\hline Up regulated & 1 \\
\hline & 2 \\
\hline & 3 \\
\hline Down regulated & 4 \\
\hline
\end{tabular}

\begin{tabular}{|c|}
\hline Size \\
\hline 40 \\
\hline 25 \\
\hline 16 \\
\hline 11 \\
\hline 32 \\
\hline 18 \\
\hline
\end{tabular}

\begin{tabular}{c} 
p-value \\
0 \\
$1.23 \mathrm{e}^{-05}$ \\
$2.91 \mathrm{e}^{-07}$ \\
0.000642 \\
$2.80 \mathrm{e}^{-09}$ \\
$1.46 \mathrm{e}^{-07}$ \\
\hline
\end{tabular}

The RPS3 gene is the major gene in the first sub network, among the genes with increasing expression. Ribosomes that catalyze protein synthesis consist of a small subunit of size 4OS and a large subunit of size 60S. RPS3 encodes a ribosomal protein that is part of the 40S subunit belonging to the family of PS3 ribosomal proteins. This gene is essential for the biogenesis of ribosomes. This protein is reportedly found in the nucleus and cytoplasm of oocytes and embryos. Also, the RPS3 is involved in the formation of new spindles in mitosis [14, 15]. Destruction of RPS3 results in inhibition of the mitotic metaphase stage, similar to the mTOR-mediated inhibition in the cow oocyte [16].

The NUSAP1 gene is an important gene in the second sub network of genes with increased expression. In a study by E. Orozco-Lucero, this gene was identified as an important nuclear gene involved in the M-II stage of oocyte maturation [17]. Also, Torner's 

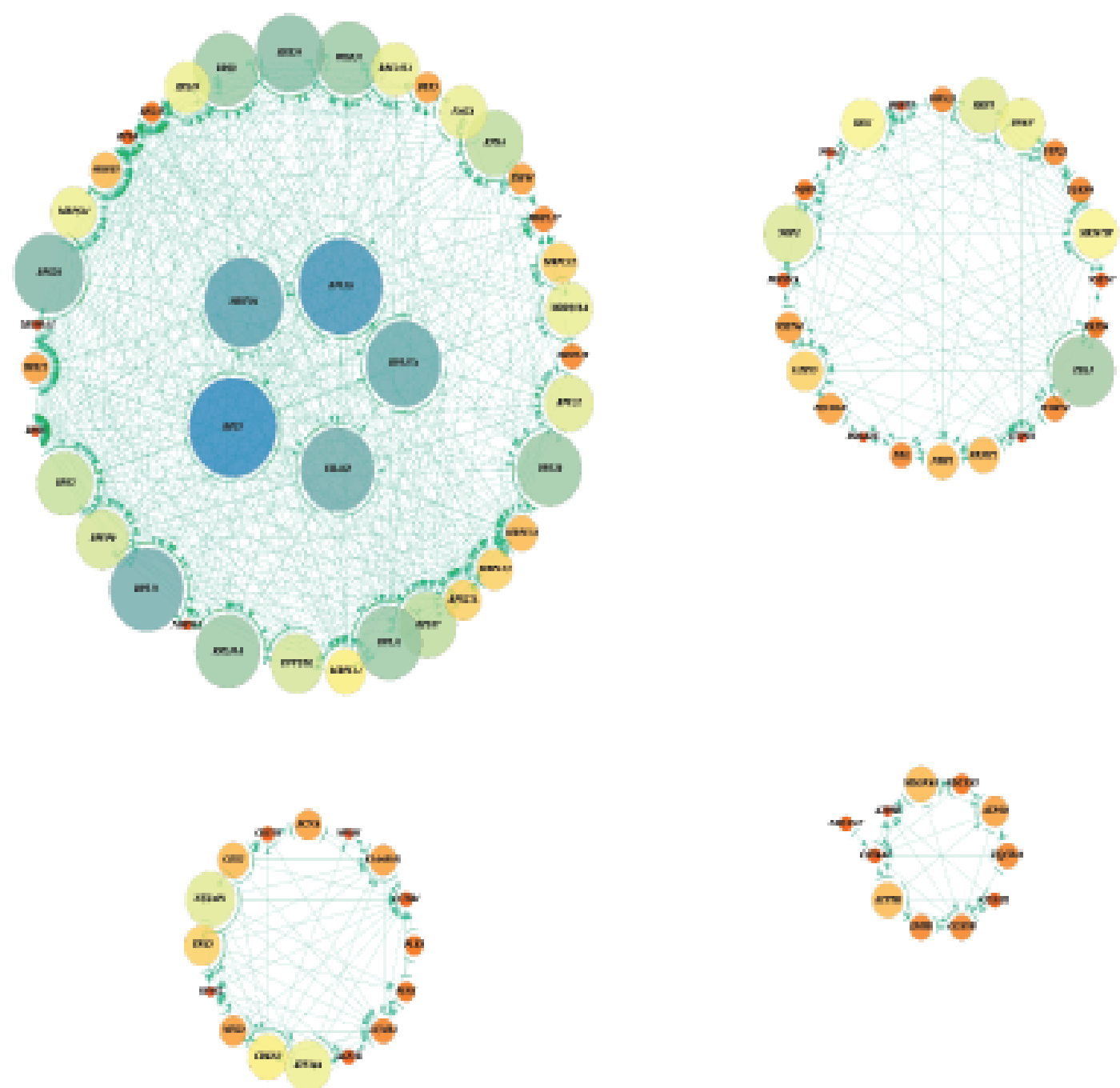

Figure 2: Up-regulated sub-network 1, 2, 3 and 4. Important nodes that have increased expression in the oocyte maturation process are shown in the four subnetworks. The RPS3 is the major gene in the first subnetwork and is essential for the biogenesis of the ribosomes. The NUSAP1 gene is the important gene in the second subnetwork and is a Nuclear Effective Gene for regulating the cell cycle in the oocyte maturation process. TBL3 is an important gene identified in subnetwork 3 and is associated with cell proliferation or biosynthesis of the ribosome. ATP5H is an important gene in the fourth subnetwork which plays an important role in oxidative phosphorylation.

study showed that the NUSAP1 gene is a nuclear effective gene important for regulating the cell cycle in the oocyte maturation process [18]. NUSAP1 is reported to be a nucleic spindle-dependent protein that plays an important role in the microtubule structure [19]. This cellular nucleus and spindle-dependent protein has recently been shown to be effective as a chromatin and microtubule binding protein that occurs during the nuclear interphase stage. Reducing nuclear resistance caused by this gene causes the spindles to organize in an incorrect fashion. Irregular formation of the spindle results in inappropriate division of the chromosome and blockage of cell proliferation. This gene has two direct effects on microtubules, in vitro. Firstly, it increases the stability of microtubules 
against degeneration and secondly, it can cross-link large number of microtubules into aster-like structures, thick fibers, and networks [20].

TBL3 is an important gene identified in sub network 3 of the genes with increased expression. The protein encoded by this gene is highly similar to the family of the proteins containing the WD40 repeat. The WD40 group is a large protein family with an apparent regulatory function. Members of this family are involved in signal transmission, RNA processing and gene expression regulation. The level of expression of the TBL3 gene is associated with cell proliferation or ribosome biosynthesis. It has been determined that a slight decrease in TBL3 expression in mice by shRNA has significant effects on ribosome processing. As ribosome biogenesis requires a high amount of energy and cellular biosynthesis precursors, disturbances in the regulation of rRNA precursor synthesis can have negative effects on growth, proliferation and cellular differentiation [21].

ATP5H is an important gene in the fourth subnetwork of genes with increased expression. It is encoded by the subunit $d$ of the ATP synthase mitochondrial. ATP synthase consists of two sets of multiple units, including the catalytic nuclei, F1 and membrane components, $\mathrm{FO}$ and proton channels, which play an important role in the mitochondrial electron transfer chain and oxidative phosphorylation. The mitochondrial ATP synthase synthesizes ATP by using an electrochemical proton gradient across the membrane during oxidative phosphorylation. Oxidative phosphorylation is an important focal pathway in cumulus cells. In this process, the expression of 21 proteins was significantly altered, and all these proteins were higher in the cumulus cells than in the germinal vesicle (GV). These proteins include 9 ATP synthases, in which ATP5H showed a high expression $[22]$.

\subsection{Network analysis of miRNA of up-regulated genes}

In the network analysis of miRNA of up-regulated genes, the number of nodes and edges were determined to be 306 and 1536, respectively. Based on the available data and node size in Figure 3, the bta-miR-10b-5p was identified as the most important miRNA gene in the network. The presence and expression of processed miRNA genes in primary embryos and oocytes indicate the involvement of miRNAs in oocyte growth and maturation, fetal growth, stem cell differentiation, and implantation [23, 24]. In a study to identify the miRNAs in cow ovary oocytes, a miRNA library of cow embryo ovary was constructed. An analysis of random sequences from the genomic library identified 679 miRNA sequences, which included 58 different cow miRNAs. Among the distinct 
miRNAs, 42 known bovine miRNAs were available in the miRBase database, with 15 new miRNAs among the remaining 16 miRNAs consistent with miRNAs identified in other species. Only one new miRNA did not match any miRNAs in the database. Analysis of the expression of 58 miRNAs in embryonic ovaries and their comparison with somatic tissues, showed that they were mainly expressed in embryonic ovaries. Analysis of more than eight miRNAs in oocytes at the GV stage has identified the micro-RNA bta-miR-10b as abundant in oocytes at the GV stage. These miRNAs were observed during maturity of the oocyte and pre-implantation development of the cattle fetus, with abundant expression in the GV stage and in the oocyte at the Mll stage, as well as in the embryo in the early stages. This gene has a role in the nutritional and regulatory function of oocytes as well as in the differentiation of fundamental cells [25].

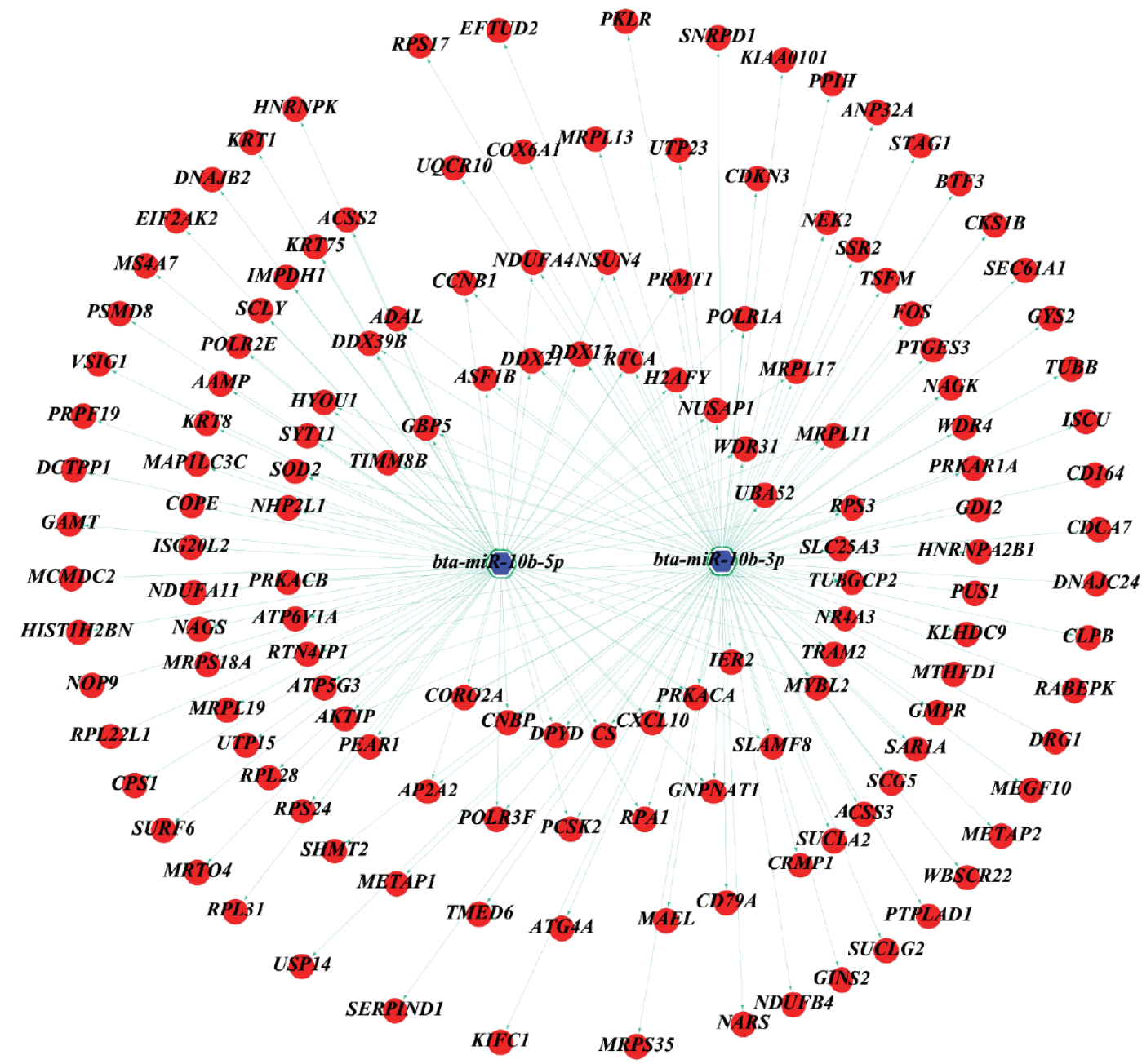

Figure 3: miRNA-up-regulated miRNA. Important nodes that have increased expression in the miRNAmiRNA network of oocyte maturation are shown. bta-miR-10b-5p gene has been identified as the most important microarray gene in the network. The role of this gene in the nutritional and regulatory function of oocytes as well as the differentiation of fundamental cells can be achieved. 


\subsection{Gene ontology of up-regulated sub-networks}

The results of the gene ontology analysis of the protein interaction network associated with the genes with increased expression are presented in Table 2 . These genes are involved in the biological pathways of mitochondrial ATP synthesis coupled to proton transport, cell division, rRNA processing, and in the positive regulation of rRNA processing.

TABLE 2: Gene ontology of significant up and down regulated sub-networks.

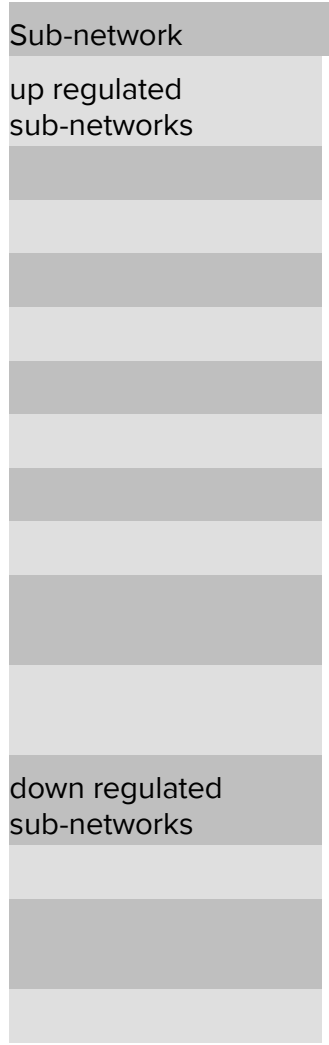

\begin{tabular}{|c|c|}
\hline 1 & GO ID \\
\hline & 6364 \\
\hline & 6413 \\
\hline 2 & 70126 \\
\hline & 27 \\
\hline 3 & 51301 \\
\hline & 86 \\
\hline 4 & 7270 \\
\hline & 6123 \\
\hline 1 & 10501 \\
\hline & 6364 \\
\hline & 6614 \\
\hline
\end{tabular}

GO Name
rRNA processing
translational initiation
Mitochondrial translational termination
mitochondrial translational elongation
ribosomal large subunit assembly
positive regulation of rRNA processing
cell division
G2/M transition of mitotic cell cycle
mitotic sister chromatid segregation
mitochondrial ATP synthesis coupled
proton transport
mitochondrial electron transport,
cytochrome c to oxygen
RNA secondary structure unwinding
rRNA processing
SRP-dependent co-translational protein
targeting to membrane
translation

$p$-value
0
0
$6.00 e^{-14}$
$8.88 e^{-16}$
$9.90 e^{-08}$
$4.59 e^{-07}$
$1.36 e^{-09}$
$3.91 e^{-09}$
$6.53 e^{-09}$
$6.11 e^{-13}$
$2.42 e^{-10}$
$2.86 e^{-12}$
$1.06 e^{-10}$
0
$3.33 e^{-16}$

In the biological pathway of mitochondrial ATP synthesis coupled proton transport, proton propulsion is used to transfer ATP from the matrix to cytosol. The ADP/ATP pair transfers the ADP molecule to the matrix for the excretion of an ATP molecule from mitochondria. On the other hand, the phosphate group is required to produce ATP and it is transferred to the matrix with a proton. Therefore, the combined performance of these two transducers results in the exchange of ADP and cytosolic $P_{i}$ with the matrix ATP, which is accomplished by a proton charge in the matrix. Hence, for the production of any ATP molecule, the transfer of four protons from the space of the two membranes into the matrix is required. Therefore, the genes associated with oocyte maturation show increased expression. It has been determined that oocyte maturation requires more energy with energy reaching a peak during ovulation [26]. Since fetal mitochondrial 
replication is not performed until the blastocyst stage, mature oocytes (MII), fertilized oocytes, and early embryos are dependent on mitochondrial energy storage during ovulation $[27,28]$.

Genes have increased expression in the biological pathways of cell division, demonstrating the important role of cell division in the developmental stages of oocyte. The development of oocyte begins from the embryo and continues throughout life. The mitotic divisions (cell proliferation) end in most species before birth. The last mitotic division that produces primary oocytes is important because the oocyte enters the earliest cell division of the meiosis. Meiosis 1 stops at this stage, and continues until the first gonadotropin surge that occurs at maturation. At the time of ovulation, the gonadotrophin surge continues to dominate, and the oocyte enters the metaphase 2 cell division stage. The final maturation of oocyte is accomplished by the introduction of sperm into oocyte. Oocyte growth does not occur in the absence of granulosa cells. In oocyte growth stage, the cytoplasm volume increases 50 -fold. Granulosa cells provide the material needed for the synthesis of zona pellucida in oocytes. When the oocyte reaches a predetermined amount, the ability to resuscitate meiosis is created. Cellular bonds between granulosa cells and oocytes disappear, shortly after the Luteinizing Hormone (LH) surge. With the breakdown of these bonds, the effects of the meiosis inhibitory elements are removed and the oocyte is prepared to be fertilized [29].

Increased gene expression in oocyte maturation plays an important role in the biological pathway and positive regulation of rRNA processing, which indicates the role of rRNAs in oocyte maturation. In the process of gametogenesis, the oocytes and spermatocytes are subjected to significant molecular, cellular and structural changes. In particular, the oocytes increase by a 100 -fold, and various other components such as RNAs, proteins, lipids, carbohydrates, vitamins, and hormones that are essential for the proper development of the fetus, are also stored [30]. Ribosomal rRNAs or rRNAs are the main components of the ribosomes, and the name ribosome is also derived from ribonucleic acid (RNA) which is essential for protein synthesis in all living organisms. One of these rRNA molecules, which is important in oogenesis is 5S rRNA. Interestingly, two different types of 5S rRNA genes with variable sequences have been revealed in Xenopus laevis. One of them is only expressed in oocytes and the other is expressed in both somatic cells and gonads. Only oocyte $5 \mathrm{~S}$ rRNA is explicitly accumulated in ovaries. The oocyte 5S rRNA undergoes substantial mobilization and reductions to the basal level when oocytes enter vitellogenesis with this large amount of 5S rRNA being incorporated into the ribosomes in the amplified nucleoli [31]. Mammalian oocytes undergo active transcription during growth, but after resuscitation of meiosis, oocyte genes use 
RNAs synthesized by the mother to reach the transcriptional stage. The development of meiosis and the production of the primary embryo in the ovum is regulated by the level of the mRNA, the translation process and post-translational changes, which is directly related to the ribosomes and is relevant to the role of the rRNA. The ability to resuscitate meiosis in the ovum at the end of the growth stage (from the intestinal follicles) to the time of maturation (meiosis in the metaphase stage (II) [32, 33], depends on the rate of transcription in the oocyte and the complete activation of the rRNA in the nucleus of the gametes [34, 35], transcription of rRNA genes and processing of rRNA depends on the formation of pre-ribosomal particles in the nuclear space [36]. The three main nucleolar compartments are the fibrillar centers (FCs), the surrounding dense fibrillar component (DFC), and the granular component (GC) [37]. FCs are enzyme machineries that control the transcription process, the DFC performs the primary transcription, and the GC represents processed transcripts related with the proteins in the form of preribosomal particles. Beginning of rRNA gene transcription requires the formation of the transcription initiation complex, consisting of RNA polymerase I (RNA Pol I), RNA Pol I-associated factors, and at least two specific transcription initiation factors, the speciesspecific selectivity factor 1 (SL-1) and the upstream binding factor [38]. Construction of the transcription initiation complex needs interaction between RNA Pol I and an RNA Pol Iassociated factor, PAF53, which allows progression of the interaction between RNA Pol I and UBF. The mechanism by which UBF activates rRNA gene transcription includes construction of dimers, binding of UBF to the upstream promoter element of the rRNA genes and interaction between UBF and the rRNA gene transcription initiation factor SL-1 [39]. SL-1 is a multimeric protein containing the TATA-binding protein (TPB) and at least three TPB-associated factors that are specific for transcription by RNA Pol I [40]. The rRNA gene promoters lack a TATA-box, and SL-1 by itself does not bind to the rRNA gene core promoter element [41]. Consequently, binding of SL-1 is mediated by the interaction with UBF. After bound to UBF, SL-1 is in direct contact with the rRNA gene promoter and directs promoter-specific beginning of transcription and, thereby, rRNA synthesis [42].

\subsection{Functional network of up-regulated sub-networks}

The information on the functional network related to the genes with increased expression is shown in Table 3. According to Table 3, the genes in the oxidative phosphorylation pathway with increased expression, play a role. In fact, the quality of oocyte is considered an important factor for in vitro fertilization (IVF). Extensive observation showed that mitochondria play an important role in oocyte cytoplasm, because it can 
provide ATP for the development, growth and maturation of embryos before fertilization, as well as acting as a calcium store and an intracellular pro-apoptose. The oxidative mitochondrial phosphorylation is the primary source of ATP. The importance of producing mitochondrial ATP for energy supply during oocyte maturation and fertilization has also been identified. Since the glycolytic rate in the ovum is low, ATP is mainly provided by mitochondrial oxidative phosphorylation $[43,44]$. The rapid reduction in ATP during oocyte maturation indicates that oocyte consumption is high and since ATP supply depends on oxidative mitochondrial phosphorylation, which indicates the importance of mitochondrial function in oocyte maturation.

TABLE 3: Functional network of significant up regulated subnetworks.

\begin{tabular}{|c|c|c|c|c|}
\hline \multicolumn{2}{|l|}{ Significant sub-network } & Annotation (pathway/process) & $\begin{array}{l}\text { Significance } \\
\text { of network } \\
\text { distance } \\
\text { distribution } \\
\text { (XD-Score) }\end{array}$ & $\begin{array}{c}\text { Significance } \\
\text { of overlap } \\
\text { (Fisher-test, } \\
\text { q-value) }\end{array}$ \\
\hline \multirow{8}{*}{$\begin{array}{l}\text { up regulated } \\
\text { subnetwork }\end{array}$} & 1 & Ribosome & 0.9198 & $6.40 e^{-13}$ \\
\hline & 2 & RNA polymerase & 0.9549 & 0.00011 \\
\hline & & Pyrimidine metabolism & 0.2779 & 0.00215 \\
\hline & & Purine metabolism & 0.1615 & 0.00682 \\
\hline & 3 & Mismatch repair & 0.380 & 0.85085 \\
\hline & & Progesterone-mediated oocyte maturation & 0.31 & 0.00378 \\
\hline & & Cell cycle & 0.284 & 0.00027 \\
\hline & 4 & Oxidative phosphorylation & 0.754 & $8.70 e^{-17}$ \\
\hline \multirow{2}{*}{$\begin{array}{l}\text { down regulated } \\
\text { subnetwork }\end{array}$} & 1 & RNA polymerase & 0.6366 & 0.016 \\
\hline & 2 & Ribosome & 0.817 & $3.50 e^{-11}$ \\
\hline
\end{tabular}

The progesterone-mediated oocyte maturation pathway is also associated with increased expression of genes. Gonadotropins, steroids, and chemical compounds are one of the effective factors in the maturation of the oocyte in the ovary. High concentrations of these hormones increase oocyte maturity and the chance of fertilization $[45,46]$. The production of mature oocytes and biosynthesis of steroid hormones in the ovary is an essential process in the ovary. Fertile oocyte maturation is a complicated process that depends on the development and proper growth of oocytes in the specific environment of ovarian follicles. During ovulation, the mature and ripe follicles are torn releasing oocytes. The FSH hormone secreted by the pituitary gonadotropes binds to its receptors in the gonads and stimulates the production of steroid hormones and gametes [47]. Progesterone, the steroid hormone (P4), plays an important role in ovulation, development and maintenance of pregnancy, and in the development of breast glands $[48,49]$. Recently, several new roles for P4 have been shown during 
fertilization, including oocyte growth and maturation [50, 51], sperm release from the sperm reservoir, and increased sperm motility $[52,53]$. The expression of P4 receptor nuclei (PR) is induced by LH and FSH in cumulus cells, and a high level of P4 is produced by cumulus cells resulting in the resumption of oocyte meiosis and oocyte maturation, It has been shown that there are at least three unique mechanisms for the role of P4 on oocyte maturation, the direct effect of P4 on the oocyte, action of P4 on cumulus cells which in turn leads to oocyte meiosis resumption, and the secretion of P4 from the ovary, which causes oocyte maturation [54].

\subsection{PPI network of down-regulated genes}

The gene interaction network of a set of genes with reduced expression during oocyte development due to the effect of the FSH hormone is presented in Figure 4 and 5 and the genes involved are listed in the Table 1. The Clusterone software shows the interaction of the proteins associated with decreased expression of genes identified in two significant sub networks. The number of nodes in the first sub network was 32 with a significance level of $2.80^{-09}$ and that in the second sub network was 18 with the significance level being $1.46^{-07}$. The number of edges determined was 1209 .

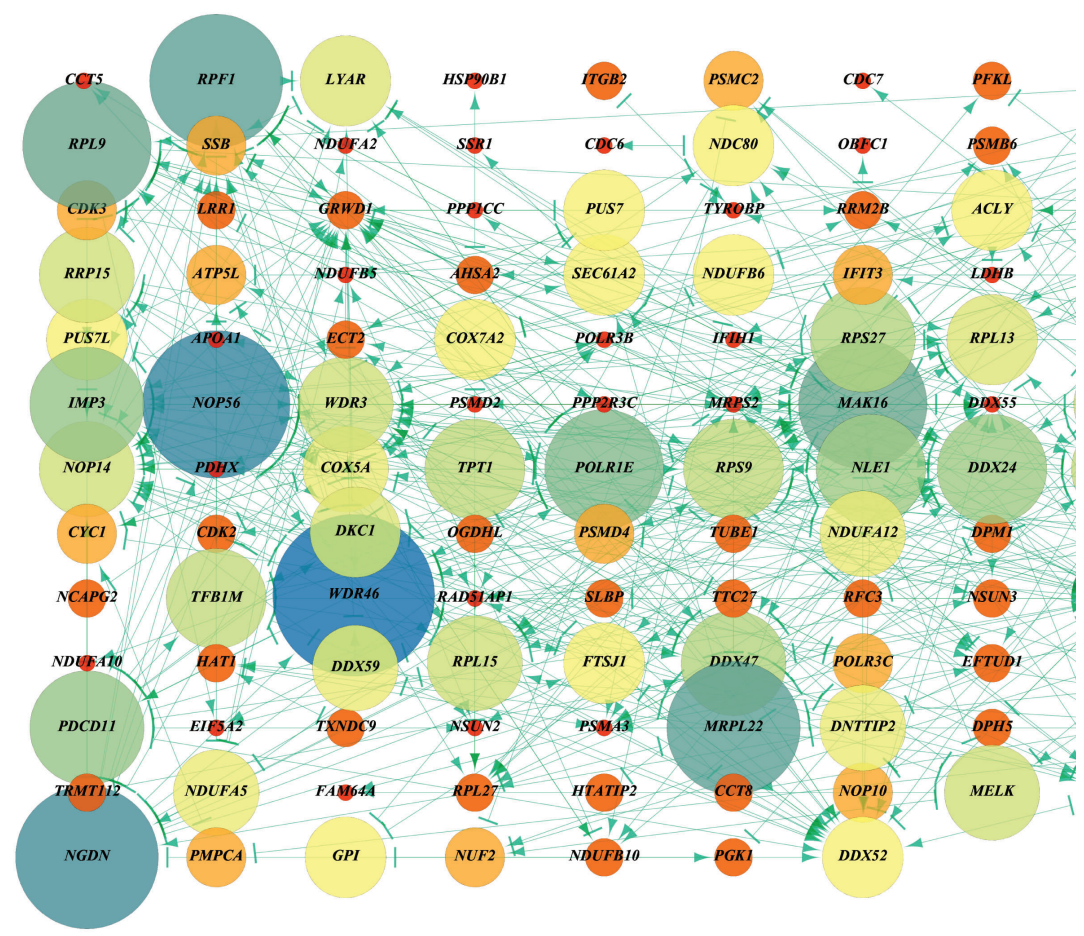

Figure 4: PPI network of down regulated genes. The general set of the decreased expression genes have been shown in the oocyte maturation process. 


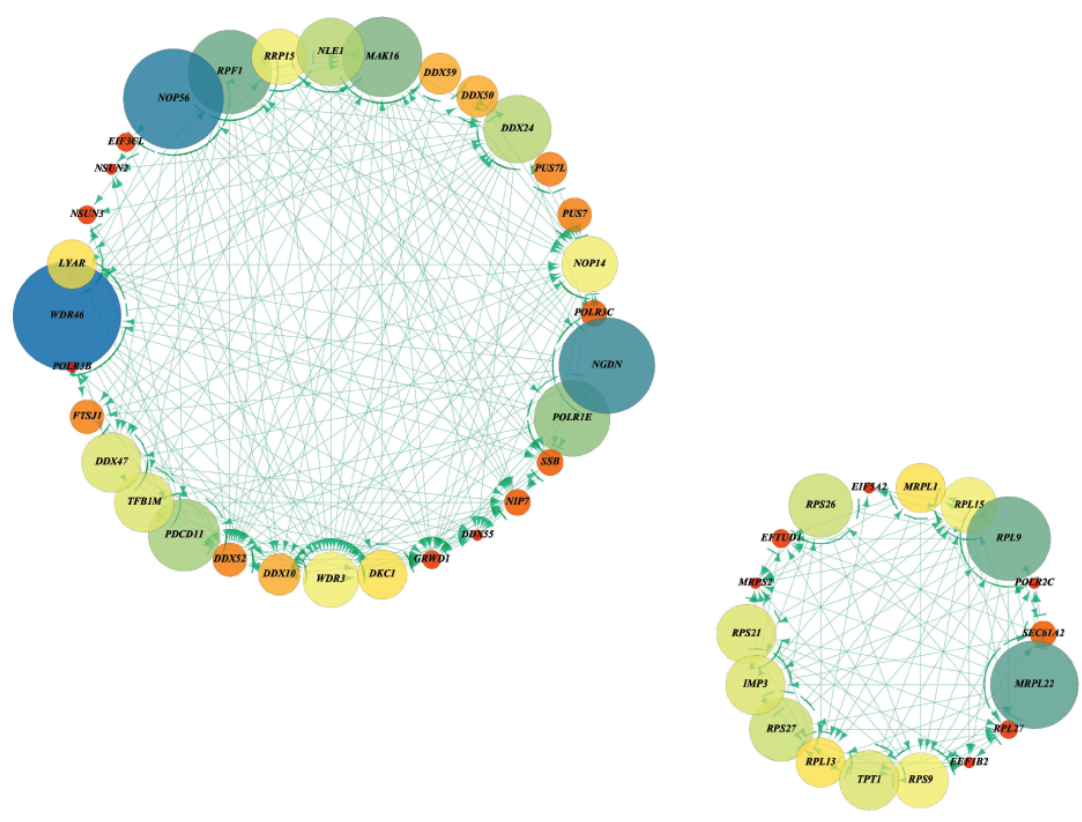

Figure 5: Down-regulated sub-network 1\&2. Important nodes that have decreased expression in the oocyte maturation process are shown in two subnetworks. The WDR46 gene has been found to be the major gene of the first subnetwork that plays an important role in generating a balance in the synthesis of rRNA. The important gene in the second subnetwork that creates a balance in energy production by eliminating mitochondria in the oocyte maturation process.

The WDR46 gene has been found to be the major gene in the first subnetwork of genes with decreased expression. In the absence of WDR46, the coupled pair of nucleolin and DDX21 involved in rRNA $18 \mathrm{~S}$ processing was subjected to change. Since, the rRNA molecules are substantially present in oogenesis, the proper transfer of nucleolin and DDX21 after cell division to female cells is guaranteed by WDR46. The reduction of this gene in the oocyte maturation process is likely to play an important role in balancing the synthesis of rRNA [55].

The important gene in the second sub network associated with the decreased gene expression is MRPL22. Gene expression reduction is reported to be accompanied by an increase in oxygen free radicals, which ultimately results in the destruction of mitochondria [56]. The inadequate function of mitochondria as an organ that plays an important role in energy metabolism can lead to pathological conditions. Mitochondrial diseases are effectively caused by disturbances in the electron transport chain and an imbalance between the division and mitochondrial expansion. The oxidative stress caused by the continuity of electrons from NADH leads to an increase in reactive oxygen species (ROS) production and mitochondrial damage by ROS. Thus, reduced MRPL22 expression creates a balance in energy production by eliminating mitochondria in the oocyte maturation process [57]. 


\section{7. miRNA-mediated down-regulation of mRNA}

In the network analysis of miRNA-mediated down-regulation of genes, the number of nodes and edges determined were 84 and 262, respectively. Based on the available data and node size in Figure 6, miR-29b-2-5p was identified as the most important miRNA in the network of genes with decreased expression, during oocyte maturation. In the old ovum, a significant reduction in the amount of mRNA, anti-apoptotic protein $\mathrm{Bcl}-2$, and active caspase protein has been shown $[58,59]$. Since the role of miRNAs in stimulating the expression of pro-apoptotic or an-apoptotic genes in order to produce antiapoptotic effects has been identified [60], miR-29b-2-5p is also an anti-apoptotic gene. Apoptosis is suppressed by anti-apoptotic genes; however, increase in the expression of these genes causes cell death. Therefore, the expression of this gene should be reduced to regulate apoptosis [61]. If fertilization does not occur after ovulation, mammalian eggs are increasingly exposed to early aging. It has been shown that the oocyte undergoes apoptosis after ovulation and has harmful effects on fetal development [62].

\subsection{Gene ontology of down-regulated sub-networks}

The results of the gene ontology analysis of the protein-protein interaction network associated with the genes with decreased expression are presented in Table 2. Based on these results, it has been found that these genes are involved in the signal recognition particle (SRP)-dependent pathways of co-translated proteins targeting the membrane and RNA secondary structural unwinding. SRP-dependent co-translational protein targeting the membrane in all cells, reach the target site after transfusion or at the same time [63]. The SRP is a ribonucleoprotein device that directs the spatially corrected synthesis and trafficking of membrane and secreted proteins. In vertebrates, the SRP consists of a 300 nucleotide-long RNA and six proteins. The newly formed protein has a hydrophobic signal sequence. This sequence is driven by two parts toward the endoplasmic reticulum membrane: 1) SRP present in cytosol and attached to the ribosome when the sequence is exposed; and 2) SRP receptor located in the membrane of the network. The $\mathrm{N}$-terminal sequence is based on the signal polypeptide, which allows the collection of ribosomal chain strands (called RNCs or bursts) to be targeted within the membrane during interaction with the SRP receptor (SR) [64]. In a study of SRP in large chromosomal nuclei in Xenopus laevis oocytes, an initial step in the activity of SRP is the binding of the SRP19 protein to the SRP RNA. In a particular study, SRP19 protein was injected into the oocyte cytoplasm, followed by introduction into the nucleus, 


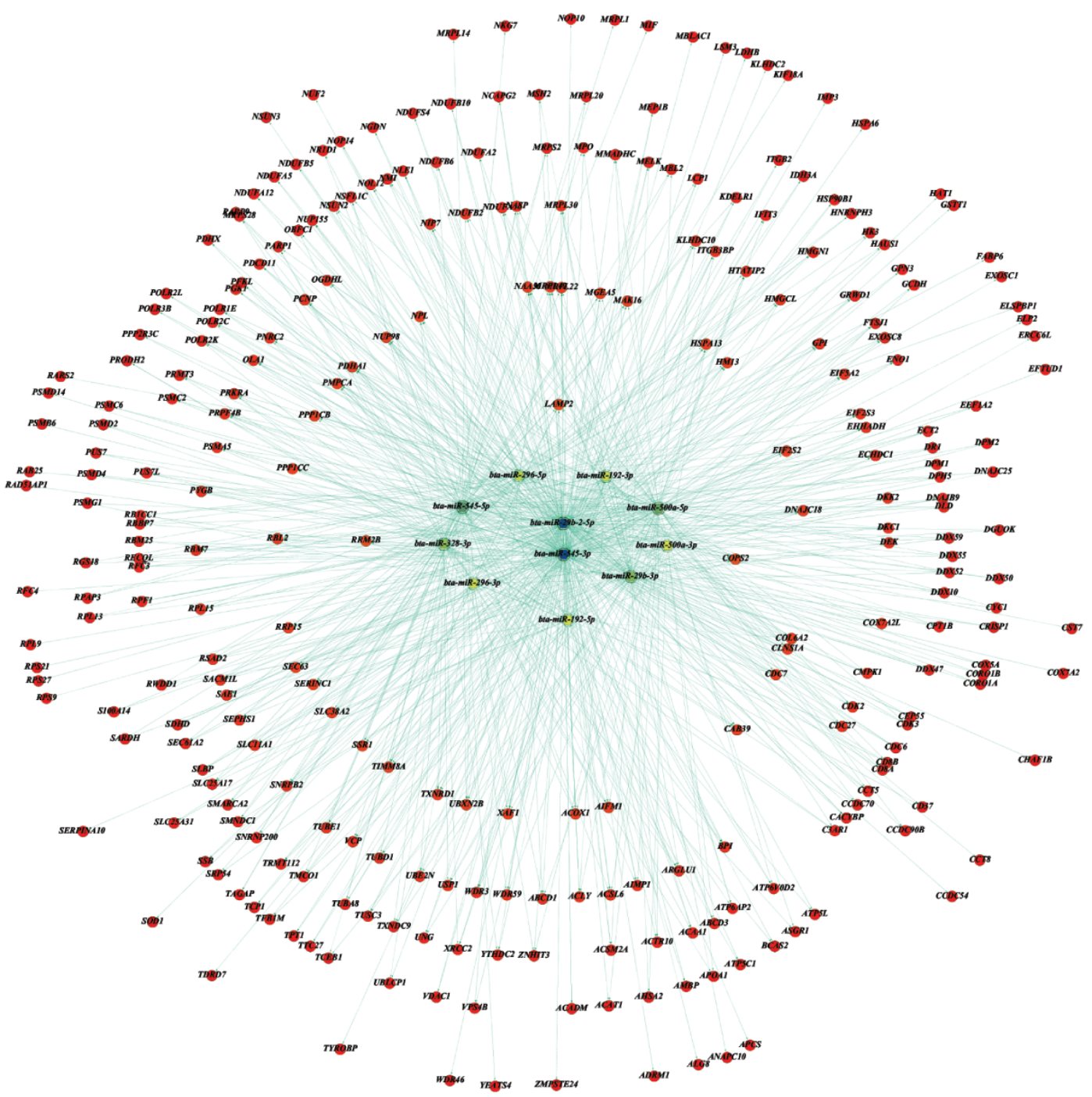

Figure 6: miRNA-down-regulated mRNAs. Important nodes that have decreased expression in the miRNAmiRNA network of oocyte maturation are shown. miR-29b-2-5p has been identified as the most important microarray gene in the network, which plays an important role in the anti-apoptotic process.

causing a proliferation of the nucleus. After reviewing the proliferated nuclei, a riboprotein complex with SRP sedimentation characteristics was observed. These results suggest that the amplified nucleoli of Xenopus oocytes yield maternal stores not only of ribosomes, which is the classical product of nucleoli, but also that of SRP. This is the default evolutionary strategy for translation and protein synthesis to store the desired proteins in early embryo development. In the growth stage and the stage before puberty, oocyte generates and stores a large amount of mRNA (in the process of transcription and assisted enzyme RNA polymerase) and proteins (in the process of translation with the help of ribosomes), thus producing the protein during oocyte maturation only for specific mRNAs, which are active because of reduced translation during oocyte maturation, 
Therefore the effective genes also have decreased expression in the protein transfer pathway [63].

In the biological pathway of RNA secondary structure unwinding, genes that have been effective in oocyte maturation have decreased expression. An important step in the synthesis of eukaryotic protein is the binding to the small subunit of the ribosome to the mRNA. This process requires at least three primary factors, elF-4A, elF-4B and elF-4F. The two-string and secondary structure of RNA prevents translation and the formation of the primary complex. This stem structure prevents the interaction of the mRNA with the small subunit $40 \mathrm{~S}$ of the ribosome. As a result, translocation is more sensitive to the secondary structure at the entry site for ribosomes, which is the end of the 5'-mRNA. These factors are believed to bind to the end of 5'-eukaryotic mRNAs and use the energy derived from ATP hydrolysis to dissolve the secondary structure of the 5'- end of the mRNAs. Thus, this facilitates the connection to the small ribosomal subunit. It has been shown that two distinct complexes are formed between the initiator and the RNA. These complexes share the process of dissolving the end portion of the RNA. It was found that the elF-4F and elF-4B complex, which is probably an active helicase and moves along the two strands of RNA, separates the alternating base nucleotides, and is then released from the RNA. Thus, the translation of the genes begins after the dissolution of the twostrand structure of the mRNA. Since the translation of the gene is limited during oocyte maturation, the genes involved in this pathway have decreased expression [65].

\subsection{Functional network of down-regulated genes}

The functional pathway of ribosomal and RNA polymerase shows the involvement of genes with either increased or decreased expression. Primary oocyte that is created in the embryonic period and after the division of ovogonia, begins the first meiosis and remains in the prophase meiosis 1 stage. At the time of maturation, the initial oocyte begins the growth stage, followed by the maturation stage. At the stage of growth and before entering maturation stage, oocyte builds and stores a large amount of mRNA (in the process of transcription and assisted enzyme RNA polymerase) and protein (in the process of translation with the help of ribosomes). RNA, which is accumulated inside the oocyte cytoplasm, plays an important role in protein synthesis after fertility and during development before embryo implantation [66, 67]. The oocyte growth period is characterized by a relative fixed pattern of gene expression along with the accumulation of macromolecules (for example, RNAs and proteins), since production of RNA decreases when oocytes enter puberty stage, eventually stopping. On the other hand, 
oocytes require a certain level of mRNA to reach the maturity stage [68]. The role of the ribosomal and RNA polymerase seems important since oocyte is inactive for transcription during maturation $[69,70]$. Therefore, translation and transcription are important and protected in oocytes. A protective evolutionary mechanism is the transcription of mRNA polyadenylation $[71,72]$. During the polyadenylation of the 3'-end, newly transcribed mRNAs are equipped with a dedicated structure. Additional mechanism is the phosphorylation and dephosphorylation of a number of different initiation factors and their regulators (i.e., elF2, elF2B, elF3, elF4E, and 4E-BP1) as well as ribosomal proteins $[73,74]$

Several types of mRNAs have been identified that require translation control for the fetus. In Zenopus oocytes, the mechanism for the control of the translation of the maternal mRNA transcript has been identified during puberty by variations in the polyadenine tail. Algorithm and characteristics of stem cells in Drosophila are mainly created by translation adjustments depending on the position of the mother's transcribed mRNAs that are contained within the egg. This translation setting is often accompanied by mechanisms that focus on the mRNA within the ovulation range, and thus the protein is expressed in low concentrations, which is harmful. Stopping of translation is particularly complex in developing oocytes, with translations being active only for specified mRNAs [75]. Increase and decrease in the expression of effective genes in oocyte maturation is explained in the translation and gene expression for equilibrium and regulatory mechanisms.

\section{Discussion}

The production of cow embryos by IVF is almost entirely dependent on the use of immature oocytes derived from the in vitro maturation (IVM) process. The success rates of IVMIVF at the blastocyst stage are relatively low (less than $40 \%$ ), especially when oocytes are collected from ovaries under different treatments and from slaughterhouses. In the last decade, stimulator protocols have been improved and IVM-IVF has become more common in infertile cattle treatment. The cultures of oocytes derived from livestock by selecting ovum from FSH-treated ovaries and after a 44-hour coasting period following the last injection of FSH follows the concept of coasting period proposed 10 years ago, which had a significant effect on blastocyst and pregnancy rates [76]. In the recent study used in this dissertation, the following protocol was followed. Oocytes susceptible to the coasting period have been optimized by culturing at the moment of follicular differentiation, resulting in a very high blastocyst rate (above $75 \%$ of the best coasting period 
and $100 \%$ in some livestock) using a coasting period between 44 and 68 hours with a pregnancy rate of over $50 \%$ [77]. Despite such success, the key factors in improving the quality of oocyte have not yet been determined. Challenges in this regard are related to a limited number of oocytes available for molecular or chemical characterization, with oocytes containing only a small amount of RNA or protein [78]. The majority of these were selected during growth and change and had a lower maturity rate [79]. Oocytes are physiologically inactive in cattle as well as in many other species, such as showing clear decrease in RNA synthesis in oocytes with diameters of more than $110 \mathrm{~nm}$ [80]. Also, the final growth phase shows a graduated mode of active DNA transcription to a nearly inactive state during the last phase of follicular growth [81]. Therefore, for the formation of the embryo, the accumulation of transcribed DNA in oocyte relies on a number of chemical modifiers, such as polyadenylation, prior to stopping and stabilizing. These modifiers have been well identified in laboratory species such as frog. In various studies, the GV oocyte exhibits a relatively stable image for studying the differences in the level of mRNA with regard to the susceptibility of oocytes to living beings [82]. Few studies have been done at different stages on the frequency of mRNAs in oocytes using a microarray approach. The comparison of pre-maturation oocytes with adult GVs with microarray technique showed that approximately 200 transcripts were different in these comparisons [2]. They studied the effect of follicular conditions by using cDNA microarray and identified 51 genes that had a significant difference in their mRNA levels between the oocytes in the growth phase compared to the dominance phase [83]. In a study by Nivet, different coasting period led to different oocyte quality, measured in the first 20 hours and in the last 92 hours of the coasting period, compared with the high quality observed in the median period (44 to 68 hours), which was lower [77]. A lot of studies have been done on the structure and function of oocytes, but the process of oocyte maturation is still not clear. This study for the first time has used data from different bases and combined these for a more comprehensive analysis of oocyte maturation under FSH treatment in the GV stage after a coasting period (normal conditions, 44 and 68 hours before maturity and 20 hours after puberty up to 92 hours) using microarray data provided by Laberquo et al [8].

A comprehensive review of the gene expression network at a genomic scale in the oocyte maturation process shows the marker genes and various biochemical pathways leading to a proper understanding of the genetic quality of oocytes at maturity, which can be used in the IVM-IVF technique. In examining the genes expressed in the pathway of oocyte maturation, three groups of nuclear genes, mitochondria, and miRNA genes were determined. Oocyte maturity includes nuclear and cytoplasmic maturity, which 
are both important for embryo and fertilization. Oocyte nucleus maturation involves processes that stop meiosis in prophase 1, with oocytes advancing toward meiosis II [75] The nuclear genes with increased expression in this study have contributed to the formation and organization of nuclear microtubules. It has been determined that the nuclear maturation process depends on the formation and maintenance of a meiotic spindle and requires centrosomal proteins and regulatory proteins. Irregular formation of meiotic spindle and inappropriate division of chromosomes on the plate of metaphase spindle results in inadequate proliferation of the cell [84, 85]. In a study, oocyte maturation in mice was associated with the reorganization of the microtubule of the smooth endoplasmic system. In this process, the dispersed cytoplasmic network was converted into a dense network around the core coating and eventually became a spherical mass with a high density near the spindle in the adult oocyte [86].

The expression of the nuclear genes involved in this study was accompanied by both increasing and decreasing trends in the process of rRNA and ribosome molecules. It has been determined that oocyte builds up and stores a large amount of mRNA and protein in the growth stage before it enters the maturation stage. Since the production of RNA decreases and eventually stops when the diplotene stage passes into the maturity stage, the maternal mRNA plays an important role in the protein synthesis after fertilization and during development before embryo implantation. An ovum is a good example for controlling gene expression at the translation level, since many mechanisms that cause mRNA analysis in somatic cells do not occur in the ovum and can save large amounts of mRNA without translating $[68,87]$. Oocyte-specific maternal mRNAs are not made after activation of the embryo genome. The different kind of resistance to translation of these mRNAs is a selective mechanism and a way of eliminating protein copies which the protein derived from them are not required by the fetus [88]. It has also been determined that the progression of meiosis and the production of the primary embryo in the ovum is regulated by the level of mRNA, translation, and post-translational alteration, which is directly related to the ribosomes, and is relevant to the role of the rRNA. The ability to resuscitate meiosis in the ovum at the end of the growth stage (from the initial follicles) to the time of maturation (meiosis in the metaphase stage (II) $[32,33]$ depends on the rate of transcription in oocytes and the complete activation of the rRNA synthesis in the nucleus of the gametes $[34,35]$. Therefore, the trend of increasing and decreasing the expression of effective nuclear genes is justified in order to balance the translation process and gene expression during oocyte maturation. 
Effector genes in the oocyte maturation process that have been shown to increase in this study play an important role in the electron transfer chain and oxidative mitochondrial phosphorylation. Since mitochondria are the energy supplier of the cell, it is essential that they survive and develop. Therefore, their location and function can affect the quality of the oocyte and consequently interfere with the embryo development process. Mitochondria are involved in activating certain metabolic pathways in protein synthesis and phosphorylation in cytoplasmic maturation. The mitochondria play a very important role in supplying the energy of oocytes to complement puberty [89]. The expression of mitochondrial genes is strongly controlled by signals generated by the nucleus. Proteins encoded by DNA nuclei enter the mitochondria to control their function in a specific tissue state $[90,91]$. The transcription and mtDNA replication are interdependent. The equilibrium in the ATP production process is very important, and thus mtDNA replication is precisely regulated at the key stages of growth. For example, primary cells that are present after gastrulation, and the number of copies of mtDNA will be approximately 200 copies per primary cell. mtDNA increases with the growth of these cells. When the cells reach the first stage of the metaphase, the number of copies increase exponentially so that oocytes reach the second stage of the metaphase. It is necessary for the fertility process that the mtDNA copy number passes a certain threshold. Failure to do so causes these oocytes to fail to complete the fertility process. The important role of oxidative mitochondrial phosphorylation and the production of ATP during the early stages of embryonic development have been shown in many species, including humans [92]. With the formation of the initial follicle, it takes some time to complete the oocyte growth phase and its total volume to reach to a 100 -fold. This growth includes quantitative and qualitative changes in metabolism, structural and functional aspects of key molecules [93]. During follicle growth, the number of oocyte mitochondria rises from 10,000 to 200,000 [94]. Most mammalian cells contain several thousand mtDNA molecules, with oocytes being the richest cells in the body in terms of mtDNA content. Therefore, ovarian failure is associated with low mtDNA content, which is probably due to abnormal mitochondria and cytoplasmic maturation during oocyte maturity [95]. In general, meiosis occurs twice in the fertility process. Meiosis I occurs during ovulation and meiosis II during fertilization. The first meiosis occurs when the adult oocyte is exposed to $\mathrm{LH}$ levels of the cycle. This process requires the highest amount of energy for oocytes to collect and isolate microtubules, which play an important role in the proper separation of the chromosome. It completes meiosis II during fertilization and needs higher amount of ATP. Low ATP production in the mitochondria and defective meiosis can lead to 
oocyte maturation, lack of penetration of the first polar body, irregular distribution of chromosomes, and aneuploidy. Similar findings have been reported for mice [96].

In this study, the mitochondrial genes that have reduced expression during oocyte maturation have led to mitochondrial destruction in order to maintain balance. The mitochondrial genomic mutations can affect the components of the respiratory chain, such as cytochromes, and separate them from the respiratory chain, thereby increasing the electron leakage and excessive ROS production. It is well recognized that oxidative stress is the outcome of an imbalance between free radical production and antioxidant defense system [97]. In mitochondria, ROS accumulation may induce mitophagy that eliminates damaged mitochondria [98]. Changes in the number and size of mitochondria in the cell are generally controlled by two opposing forces, division and fusion [99]. These actions are carried out simultaneously and continuously in many types of cells, and the balance between them leads to controlling the quality of cell cycle processes, cell growth, and apoptosis. Clearly, these processes seem to require a high degree of coordination. For example, the division involves the separation of the mitochondrial outer and inner membrane and return it to the correct direction, without soluble proteins in the mitochondrial matrix or in the membrane space being damaged [100]. It can be said that the removal of damaged mitochondria and oxidized proteins supports the survival of oocytes. In this study, reducing the expression of the relevant gene and maintaining a certain level of them with mitophagy induction, may be effective in maintaining the quality of oocyte in the face of environmental stress during maturation in laboratory conditions.

In this study, a group of miRNA genes have been shown to increase oocyte maturation. The role of microRNAs (miRNAs) in the regulation of gene expression during the process of folliculogenesis and embryonic growth has been determined. These small molecules are processed from longer transcripts by the Dicer RNase III and Drosha enzymes. It has been shown that the elimination of genetic Dicer leads to non-laying, fetal mortality and thus indicates the importance of miRNA compounds in the oocyte maturation [101]. miRNAs, in addition to expression in oocytes, have been observed in cumulus cells [102]. The discovery of miRNAs expressed in cumulus cells in human oocytes indicates the role of these miRNAs in nutritional function and in the regulation of the performance between oocytes and cumulus cells [103]. The presence and expression of processed miRNA genes in oocytes and primary embryos indicates the involvement of miRNAs in oocyte growth and maturation, early embryo development, stem cell differentiation and implantation [104]. Increasing the expression of miRNA genes in this study led to the discovery of their importance in the nutritional and regulatory function 
of oocyte maturation as well as the differentiation of stem cells. Moreover, the microRNA genes in this study have been reduced in the anti-apoptotic process, since the role of miRNAs in stimulating the expression of genes with pro-apoptotic or an-apoptotic behavior in order to produce anti-apoptotic effects have been recognized [60]. The antiapoptotic members of the $\mathrm{Bcl}-2$ gene family have a vibrant role in regulating apoptosis, which promotes cell survival [105]. Apptosis is suppressed by anti-apoptotic genes, but increased expression of these genes causes cell death. Therefore, the reduction of miRNA gene expression helps maintain equilibrium.

\section{Acknowledgments}

This study was supported by a grant funded by the Agriculture Sciences and Natural Resources University of Khuzestan for a PhD study. We appreciate the contributions of the Laval University for the data generated and uploaded by them on the web.

\section{Conflicts of Interest}

The authors report no declarations of conflict of interest.

\section{References}

[1] Segal E, Friedman N, Kaminski N, Regev A, Koller D. From signatures to models: understanding cancer using microarrays. Nature Genet. 2005;37:S38-45.

[2] Patel OV, Bettegowda A, Ireland JJ, Coussens PM, Lonergan P, Smith GW. Functional genomics studies of oocyte competence: Evidence that reduced transcript abundance for follistatin is associated with poor developmental competence of bovine oocytes. Reprod. 2007;133:95-106.

[3] Bader GD, Cary MP, Sander C. Pathguide: a pathway resource list. Nucleic Acids Res. 2006;1(34):D504-6.

[4] Behdani E, Bakhtiarizadeh MR. Construction of an integrated gene regulatory network link to stress-related immune system in cattle. Genetica. 2017;145(4-5):44154.

[5] Liu J, Jing L, TU X. Weighted gene co-expression network analysis identifies specific modules and hub genes related to coronary artery disease. BMC Cardiovasc Disord. 2016;16:54. 
[6] Uddin RK, Singh SM. Hippocampal gene expression meta-analysis identifies aging and age-associated spatial learning impairment (ASLI) genes and pathways. PLoS One. 2013;8(7):e69768.

[7] Riquelme Medina I, Lubovac-Pilav Z. Gene Co-Expression Network Analysis for Identifying Modules and Functionally Enriched Pathways in Type 1 Diabetes. PLoS One. 2016; 3(11):6.

[8] Labrecque RM, Vigneault C, Blondin P, Sirard MA. Gene expression analysis of bovine oocytes with high developmental competence obtained from FSH-stimulated animals. Mol Reprod Dev. 2013;80(6):428-40.

[9] Von Mering C, Huynen M, Jaeggi D, Schmidt S, Bork P, Snel B. STRING: a database of predicted functional associations between proteins. Nucleic Acids Res. 2003;31(1):258-61.

[10] Tamás N, Haiyuan Y, Alberto P. Detecting overlapping protein complexes in proteinprotein interaction networks. Nat Methods. 2012;9(5):471-2.

[11] Assenov Y, Ramírez F, Schelhorn SE., Lengauer T, Albrecht M. Computing topological parameters of biological networks. Bioinformatics. 2008;24:282-4.

[12] Fruzangohar M, Ebrahimie E, Ogunniyi AD, Mahdi LK, Paton JC, Adelson DL. Comparative GO: A web application for comparative gene ontology and gene ontology-based gene selection in bacteria. PLoS One. 2013;8(3):e58759.

[13] Sticht C, De La Torre C, Parveen A, Gretz N. miRWalk: An online resource for prediction of microRNA binding sites. PLoS One. 2018;13(10):e0206239.

[14] Jang CY, Kim HD, Zhang X, Chang JS, Kim J. Ribosomal protein S3 localizes on the mitotic spindle and functions as a microtubule associated protein in mitosis. Biochem Biophys Res Commun. 2012;429(1-2):57-62.

[15] Susor A, Kubelka M. Translational regulation in the mammalian oocyte. Results and probl in cell differ. 2017;63:257-95.

[16] Mayer S, Wrenzycki C, Tomek W. Inactivation of mTor arrests bovine oocytes in the metaphase-I stage, despite reversible inhibition of 4E-BP1 phosphorylation. Mol Reprod Dev. 2014;81(4):363-75.

[17] Orozco-Lucero E, Sirard MA. Molecular markers of fertility in cattle oocytes and embryos: progress and challenges. Anim. Reprod. 2014;11(3):183-94.

[18] Torner H, Ghanem N, Ambros C, Hölker M, Tomek W, Phatsara C, et al. Molecular and subcellular characterisation of oocytes screened for their developmental competence based on glucose-6-phosphate dehydrogenase activity. Reprod. 2008;135(2):197-212. 
[19] Raemaekers T, Ribbeck K, Beaudouin J, Annaert W, Van Camp M, Stockmans I, et al. NuSAP, a novel microtubule-associated protein involved in mitotic spindle organization. J Cell Biol. 2003;162(6):1017-29.

[20] Ribbeck K, Aaron C, Groen AC, Santarella R, Bohnsack TB, Raemaekers T, et al. NuSAP, a mitotic RanGTP target that stabilizes and cross-links microtubules. MBoC. 2006;17(6):2646-60.

[21] Yu J, Lan X, Chen X, Yu C, Xu Y, Liu Y, et al. Protein synthesis and degradation are essential to regulate germ line stem cell homeostasis in Drosophila testes. Development. 2016;143(16):2930-45.

[22] Peddinti D, Memili E, Burgess SC. Proteomics-Based Systems Biology Modeling of Bovine Germinal Vesicle Stage Oocyte and Cumulus Cell Interaction. PLoS One. 2010;5(6):e11240.

[23] Tanghe S, Van Soom A, Nauwynck H, Coryn M, de Kruif A. Minireview: Functions of the cumulus oophorus during oocyte maturation, ovulation, and fertilization. Mol Reprod Dev. 2002;61(3):414-24.

[24] Buccione R, Schroeder AC, Eppig JJ. Interactions between somatic cells and germ cells throughout. mammalian oogenesis. Biol Reprod. 1990;43(4):543-7.

[25] Tripurani SK, Xiao C, Salem M, Yao J. Cloning and analysis of fetal ovary microRNAs in cattle. Anim Reprod Sci. 2010;120(1-4):16-22.

[26] Fleckenstein B, Daniel MD, Hunt RD, Werner RD, Falk LA, Mulder C. Tumour induction with DNA of oncogenic primate herpes viruses. Nature. 1978;274:57-9.

[27] Irvine KR, Rao JB, Rosenberg SA, Restifo NP. Cytokine enhancement of DNA immunization leads to effective treatment of established pulmonary metastases. J Immunol. 1996;156(1):238-45.

[28] Israel MA, Chan HW, Hourihan SL, Rowe WP, Martin MA. Biological activity of polyoma virus DNA in mice and hamsters. J Virol. 1979;29(3):990-6.

[29] Ahmad N, Townsend E, Dailey R, Inskeep E. Relationships of hormonal patterns and fertility to occurrence of two or three waves of ovarian follicles, before and after breeding, in beef cows and heifers. Anim Reprod Sci. 1997;49(1):13-28.

[30] Lubzens E, Young G, Bobe J, Cerdà J. Oogenesis in teleosts: How fish eggs are formed. Gen. Comp. Endocrinol. 2010;165(3):367-89.

[31] Wegnez M, Monier R, Denis H. Sequence heterogeneity of 5S RNA in Xenopus laevis. FEBS Lett. 1972;25(1):13-20.

[32] Tsafriri A, Channing CP. Influence of follicular maturation and culture conditions on the meiosis of pig oocytes in vitro. J Reprod Fertil. 1975;43(1):149-52. 
[33] Motlik J, Crozet N, Fulka J. Meiotic competence in vitro of pig oocytes isolated from early antral follicles. J Reprod Fertil. 1984;72(2):323-8.

[34] Nicole C, Kanka J, Motlik J, Fulka, J. Nucleolar fine structure and RNA synthesis in bovine oocytes from antral follicles. Gamete Res. 1986;14(1):65-73.

[35] Motlík J, Kopecný V, Trávnik P, Pivko J. RNA synthesis in pig follicular oocytes. Auto radiographic and cytochemical study. Biol Cell. 1984;50(3):229-35.

[36] Leary DJ, Huang S. Regulation of ribosome biogenesis within the nucleolus. FEBS Lett. 2001;509(2):145-50.

[37] Wachtler F, Stahl A. The nucleolus: a structural and functionallinterpretation. Micron. 1993;24:473-505.

[38] Grummt I. Regulation of Mammalian Ribosomal Gene Transcription by RNA Polymerase I. Prog Nucleic Acid Res Mol Biol. 1998;62:109-54.

[39] Bell SP, Learned RM, Jantzen HM, Tjian R. Functional cooperativity between transcription factors UBF1 and SL1 mediates human ribosomal RNA synthesis. Science. 1988;241(4870):1192-7.

[40] Comai L, Tanese N, Tjian R. The TATA-binding protein and associated factors are integral components of the RNA polymerase I transcription factor, SL1. Cell. 1992;68(5):965-76.

[41] Learned RM, Learned TK, Haltiner MM, Tjian RT. Human rRNA transcription is modulated by the coordinate binding of two factors to an upstream control element. Cell. 1986;45(6):847-57.

[42] Tuan JC, Zhai W, Comai L. Recruitment of TATA-binding protein-TAFI complex SL1 to the human ribosomal DNA promoter is mediated by the carboxy-terminal activation domain of upstream binding factor (UBF) and is regulated by UBF phosphorylation. Mol Cell Biol. 1999;19(4):2872-9.

[43] Leese HJ, Barton AM. Pyruvate and glucose uptake by mouse ova and preimplantation embryos. J Reprod Fertil. 1984;72(1):9-13.

[44] Johnson MT, Freeman EA, Gardner DK, Hunt PA. Oxidative metabolism of pyruvateis required for meiotic maturation of murine oocytes in vivo. Biol Reprod. 2007;77(1):2-8.

[45] Tarlatzis BC, Pazaitou K, Bili H, Bontis J, Papadimas J, Lagos S, et al. Growth hormone, oestradiol, progesterone and testosterone concentrations in follicular fluid after ovarian stimulation with various regimes for assisted reproduction. Hum Reprod. 1993;8(10):1612-6.

[46] Leroy JL, Vanholder T, Delanghe JR, Opsomer G, Van Soom A, Bols PE, et al. Metabolic changes in follicular fluid of the dominant follicle in high-yielding dairy cows early post partum. Theriogenology. 2004;62(6):1131-43. 
[47] Barzaghi Firooz Abadi F. Laboratory effects of ascorbic acid and FSH on oocyte maturation and mouse follicles. JSSU. 2011;19(5):586-97.

[48] Lydon JP, Demayo FJ, Funk CR, Mani SK, Hughes AR, Montgomery CA, et al. Mice lacking progesterone receptor exhibit pleiotropic reproductive abnormalities. Genes Dev. 1995;9(18):2266-78.

[49] Kim J, Bagchi IC, Bagchi MK. Control of ovulation in mice by progesterone receptorregulated gene networks. Mol Hum Reprod. 2009;15(12):821-8.

[50] Akison LK, Robker RL. The critical roles of progesterone receptor (PGR) in ovulation, oocyte developmental competence and oviductal transport in mammalian reproduction. Reprod Domest Anim. 2012; 47(4):288-96.

[51] Shimada M, Yamashita Y, Ito J, Okazaki T, Kawahata K, Nishibori M. Expression of two progesterone receptor isoforms in cumulus cells and their roles during meiotic resumption of porcine oocytes. J Mol Endocrinol. 2004;33:209-25.

[52] Hunter RHF. Sperm release from oviduct epithelial binding is controlled hormonally by peri-ovulatory Graafian follicles. Mol Reprod Dev. 2008;75(1):167-74.

[53] Bureau M, Bailey JL, Sirard MA. Binding regulation of porcine spermatozoa to oviductal vesicles in vitro. J Androl. 2002;23(2):188-93.

[54] Yamashita Y, Shimada M, Okazaki T, Maeda T, Terada T. Production of progesterone from de novo-synthesized cholesterol in cumulus cells and its physiological role during meiotic resumption of porcine oocytes. Biol Reprod. 2003;68(4):1193-8.

[55] Hirai Y, Louvet E, Oda T, Kumeta M, Watanabe Y, Horigome T, et al. Nucleolar scaffold protein, WDR46, determines the granular compartmental localization of nucleolin and DDX21. Genes Cells. 2013;18(9):780-97.

[56] Lu S, Arthos J, Montefiori DC, Yasutomi Y, Manson K, Mustafa F, et al. Simian immunodeficiency virus DNA vaccine trial in macaques. J Virol. 1996;70(6):3978-91.

[57] Alexeyev MF, Venediktova N, Pastukh V, Shokolenko I, Bonilla G, Wilson GL. Selective elimination of mutant mitochondrial genomes as therapeutic strategy for the treatment of NARP and MILS syndromes. Gene Ther. 2008;15(7):516-23.

[58] Ma W, Zhang D, Hou Y, Li YH, Sun QY, Sun XF, et al. Reduced expression of MAD2, $B C L 2$, and MAP kinase activity in pig oocytes after in vitro aging are associated with defects in sister chromatid segregation during meiosis II and embryo fragmentation after activation. Biol Reprod. 2005;72(2):373-83.

[59] Gordo AC, Rodrigues P, Kurokawa M, Jellerette T, Exley GE, Warner C, et al. Intracellular calcium oscillations signal apoptosis rather than activation in in vitro aged mouse eggs. Biol Reprod. 2002;66(6):1828-37. 
[60] Wang Z. MicroRNA: A matter of life or death. World J Biol Chem. 2010;1(4):41-54.

[61] Kim MR, Tilly JL. Current concepts in Bcl-2 family member regulation of female germ cell development and survival. Mol Cell Research. 2003;1644(2-3):205-10.

[62] Lord T, Aitken RJ. Oxidative stress and ageing of the post-ovulatory oocyte. Reprod. 2013;146(6):217-27.

[63] Sommerville J, Brumwell CL, Ritland Politz JC, Pederson T. Signal recognition particle assembly in relation to the function of amplified nucleoli of Xenopus oocytes. J Cell Sci. 2005;118(6):1299-307.

[64] Akopian D, Kuang S, Xin Z, Shu-ou S. Signal recognition particle: An essential protein targeting machine. Annu Rev Biochem. 2013;82:693-721.

[65] Jaramillo M, Dever TE, Merrick WC, Sonenberg N. RNA unwinding in translation: assembly of helicase complex intermediates comprising eukaryotic initiation factors elF-4F and elF-4B. Mol Cell Biol. 1991;11(12):5992-7.

[66] Palma GA, Arganaraz ME, Barrera AD, Rodler D, Mutto AA, Sinowatz F. Biology and biotechnology of follicle development. Sci World J. 2012;1-14.

[67] Yenuganti VR, Baddela VS, Baufeld A, Singh D, Vanselow J. The gene expression pattern induced by high plating density in cultured bovine and buffalo granulose cells might be regulated by specific miRNA species. Sci World J. 2015;61(2):154-60.

[68] Bashirullah A, Cooperstock RL, Lipshitz HD. Spatial and temporal control of RNA stability. Proc Natl Acad Sci USA. 2001;98(13):7025-8.

[69] Audic Y, Garbrecht M, Fritz B, Sheetts MD. Zygotic control of maternal Cyclin A1 translation and mRNA stability. Dev Dyn. 2002;225(4):511-21.

[70] Schultz RM. Regulation of Zygotic gene activation in mouse. Bioessay. 1993;15(8):5318.

[71] Gebauer F, Xu W, Cooper GM, Richter JD. Translational control by cytoplasmic polyadenylation of c-mos mRNA is necessary for oocyte maturation in the mouse. EMBO J. 1994;13(23):5712-20.

[72] Wahle E. A Novel poly(A) binding protein acts as a specific factor in the second phase of messenger RNA polyadenylation. Cell. 1991;66(4):759-68.

[73] Hershey WB. Translational control in mammalian cells. Annu Rev Biochem. 1991;60:717-55.

[74] Pause A, Belsham GJ, Gingras AC, Donzé O, Lin TA, Lawrence JC Jr, et al. Insulindependent stimulation of protein synthesis by phosphorylation of a regulator of 59cap function. Nature. 1994;371:162-7. 
[75] Richter J, Lasko P. Translational control in oocyte development. Cold Spring Harb Perspect Biol. 2011;3(9):a002758.

[76] Blondin P, Bousquet D, Twagiramungu H, Barnes F, Sirard MA. Manipulation of follicular development to produce developmentally competent bovine oocytes. Biol Reprod. 2002;66:38-43.

[77] Nivet al, Bunel A, Labrecque R, Belanger J, Vigneault C, Blondin P, et al. FSH withdrawal improves developmental competence of oocytes in the bovine model. Reprod. 2012;143:165-71.

[78] Gilbert I, Scantland S, Sylvestre EL, Gravel C, Laflamme I, Sirard, MA, et al. The dynamics of gene products fluctuation during bovine pre-hatching development. Mol Reprod Dev. 2009;76:762-72.

[79] Coenen K, Massicotte L, Sirard MA. Study of newly synthesized proteins during bovine oocyte maturation in vitro using image analysis of two-dimensional gel electrophoresis. Mol Reprod Dev. 2004;67:313-22.

[80] Fair T, Hyttel P, Greve T. Bovine oocyte diameter in relation to maturational competence and transcriptional activity. Mol Reprod Dev. 1995;42:437-42.

[81] LoddeV, Modina S, Maddox-Hyttel P, Franciosi F, Lauria A, Luciano AM. Oocyte morphology and transcriptional silencing in relation to chromatin remodeling during the final phases of bovine oocyte growth. Mol Reprod Dev. 2008;75:915-24.

[82] Richter JD. Cytoplasmic poly adenylation in development and beyond. Microbiol Mol Biol Rev. 1999;63:446-56.

[83] Ghanem N, Holker M, Rings F, Jennen D, Tholen E, Sirard MA, et al. Alterations in transcript abundance of bovine oocytes recovered at growth and dominance phases of the first follicular wave. BMC Develop Biol. 2007;7:90.

[84] Schatten H, Sun QY. Centrosome and microtubule functions and dysfunctions in meiosis: Implications for age-related infertility and developmental disorders. Reprod Fertil Dev. 2015;27:934-43.

[85] Bennabi I, Terret ME, Verlhac MH. Meiotic spindle assembly and chromosome segregation in oocytes. J Cell Biol. 2016;215, 611-619.

[86] Wilding M, Dale B, Marino M, di Matteo L, Alviggi C, Pisaturo ML, et al. Mitochondrial aggregation patterns and activity in human oocytes and preimplantation embryos. Hum Reprod. 2001;16(5):909-17.

[87] Curtis D, Lehmann R, Zamore PD. Translational regulation in development. Cell. 1995;81:171-8.

[88] Zeng F, Schultz RM. Requirement for RNAbinding activity of MYS2 for cytoplasmic localization and retention in mouse oocytes. Dev Biol. 2003;255:249-62. 
[89] Ferreira EM, Vireque A, Adona PR, Meirelles FV, Ferriani RA, Navarro PA. Cytoplasmic maturation of bovine oocytes: structural and biochemical modifications and acquisition of developmental competence. Theriogenology. 2009;71(5):836-48.

[90] Robin ED, Wong R. Mitochondrial DNA molecules and virtual number of mitochondria per cell in mammalian cells. J Cell Physiol. 1988;136:507-13.

[91] Shuster RC, Rubenstein AJ, WallaceBiochem DC. Mitochondrial DNA in anucleate human blood cells. Biophys Res Commun. 1988;155:1360-5.

[92] Daniel MC, Kirchhoff F, Czajak SC, Sehgal PK, Desrosiers RC. Protective effects of a live attenuated SIV vaccine with a deletion in the nef gene. Science. 1992;258:193841.

[93] Gosden RG. Oogenesis as a foundation for embryogenesis. Mol Cell Endocrinol. 2002;186(2):149-53

[94] Jansen RP, de Boer K. The bottleneck: mitochondrial imperatives in oogenesis and ovarian follicular fate. Mol Cell Endocrinol. 1998;145:81-8.

[95] Chen X, Prosser R, Simonetti S, Sadlock J, Jagiello G, Schon EA. Rearranged mitochondrial genomes are present in human oocytes. Am J Hum Genet. 1995;57:239-47.

[96] Van Blerkom J. Mitochondria in human oogenesis and preimplantation embryogenesis: engines of metabolism, ionic regulation and developmental competence. Reprod. 2004;128 (3):269-80.

[97] Khanaki K, Abedinzade M, Gazor R, Norasfard M, Jafari-Shakib R. Effect of Lamium album on mitochondrial oxidative stress in diabetic rats. Res Mol Med. 2017;5(2):9-13.

[98] Susin, SA, Zamzami N, Castedo M, Hirsch T, Marchetti P, MachoV, et al. BCL-2 inhibits the mitochondrial release of an apoptogenic protease. J Exp Med. 1996;184:1331-41.

[99] Suen DF, Norris KL, Youle RJ. Mitochondrial dynamics and apoptosis. Genes Dev. 2008;22:1577-90.

[100] Chandel NS. Mitochondria and cancer. Cancer Metab. 2014;2:8.

[101] Bernstein E, Kim SY, Carmell MA, Murchison EP, Alcorn H, Li MZ, et al. Dicer is essential for mouse development. Nat Genet. 2003;35(3):215-7.

[102] Assou S, Al-edani T, Haouzi D, Philippe N, Lecellier CH, Piquemal D, et al. MicroRNAs: New candidates for the regulation of the human cumulus oocyte complex. Hum Reprod. 2013;28(11):3038-49.

[103] Tong XH, Xu B, Zhang YW, Liu YS, Ma CH. Research resources: Comparative microRNA profiles in human corona radiata cells and cumulus oophorus cells detected by next-generation small RNA sequencing. PLoS One. 2014;9(9):e106706. 
[104] Tanghe S, Van Soom A, Nauwynck H, Coryn M, de Kruif A. Minireview: Functions of the cumulus oophorus during oocyte maturation, ovulation, and fertilization. Mol Reprod Dev. 2002;61(3):414-24.

[105] Shahedi A, Hosseini A, Khalili MA, Yeganeh F. Effects of vitrification on nuclear maturation and gene expression of immature human oocytes. Res Mol Med. 2017;5(1):27-33. 